\title{
8. PRELIMINARY EVALUATION OF DSDP CORING EXPERIENCE IN BASALT, LEG 34
}

\author{
The Shipboard Scientific Party'
}

The present interest in basement drilling in Phase 3 of DSDP and in IPOD makes it necessary to evaluate the experience in holes that have penetrated more than 20 meters of basalt. The information below is taken from data (Initial Reports and unpublished Hole Summaries) left aboard D/V Glomar Challenger, and includes sites up to Site 319 . The core summaries show only total elapsed time between successive cores on deck, and do not consider trip time or down time. We subtracted average wire line trip time (for each particular depth) from core turn around time and obtained an estimate of drilling times which include any down time. A few intervals were excluded where unusually long times suggest equipment problems.

Eleven sites, through Site 319, penetrated more than 20 meters of basalt. These are illustrated in Figure 1 which shows coring rates in meters per hour and percent core recovery as a function of basement penetration for each site: Figure 2 shows coring rates and percent core recovery in the sequence the sites were drilled. Figures 3 , 4 , and 5 are plots of various coring parameters (rate, recovery, sediment overburden thickness, age of oldest sediment above basement, and seismic velocity of recovered basement as reported in the hole summaries). Table 1 is a tabulation of the assembled data.

The following conclusions may be drawn from these data:

1) Coring rates (Figure 2) vary from $2.8 \mathrm{~m} / \mathrm{hr}$ to 7.1 $\mathrm{m} / \mathrm{hr}$ at the 11 sites, averaging $4.4 \mathrm{~m} / \mathrm{hr}$. If Site 319 is excluded, there appears to be a general increase in coring rates as a result of the 20 months of drilling experience since Site 235.

2) Percent core recovery averaged $50 \%$ for the 11 sites (Figure 2) with no improvement as a result of basement coring experience. This indicates that various experiments with different coring bits and core catchers have been unsuccessful in improving core recovery.

3) At 9 or 11 sites (Figure 1), the core recovery increased significantly below the first core. This suggests that sidewall support, which would be least at the drilling break between sediment and basalt, may be an important factor in core recovery. At the drilling break, the bit may "walk" around the bottom of the hole prior to

\footnotetext{
'Robert S. Yeats, Ohio University, Athens, Ohio (Co-Chief Scientist); Stanley R. Hart, Carnegie Institution of Washington, Washington, D.C. (Co-Chief Scientist); James M. Ade-Hall, Dalhousie University, Halifax, Nova Scotia; Manuel N. Bass, Carnegie Institution of Washington, Washington, D.C.; William E. Benson, National Science Foundation, Washington, D.C.; Roger A. Hart, Physical Research Laboratory, Ahmedabad, India; Patrick G. Quilty, West Australian Petroleum Party Ltd., Perth, West Australia, Harvey M. Sachs, Case Western Reserve University, Cleveland, Ohio; Matthew H. Salisbury, National Science Foundation, Washington, D.C.; T.L. Vallier, University of California at San Diego, La Jolla, California.
}
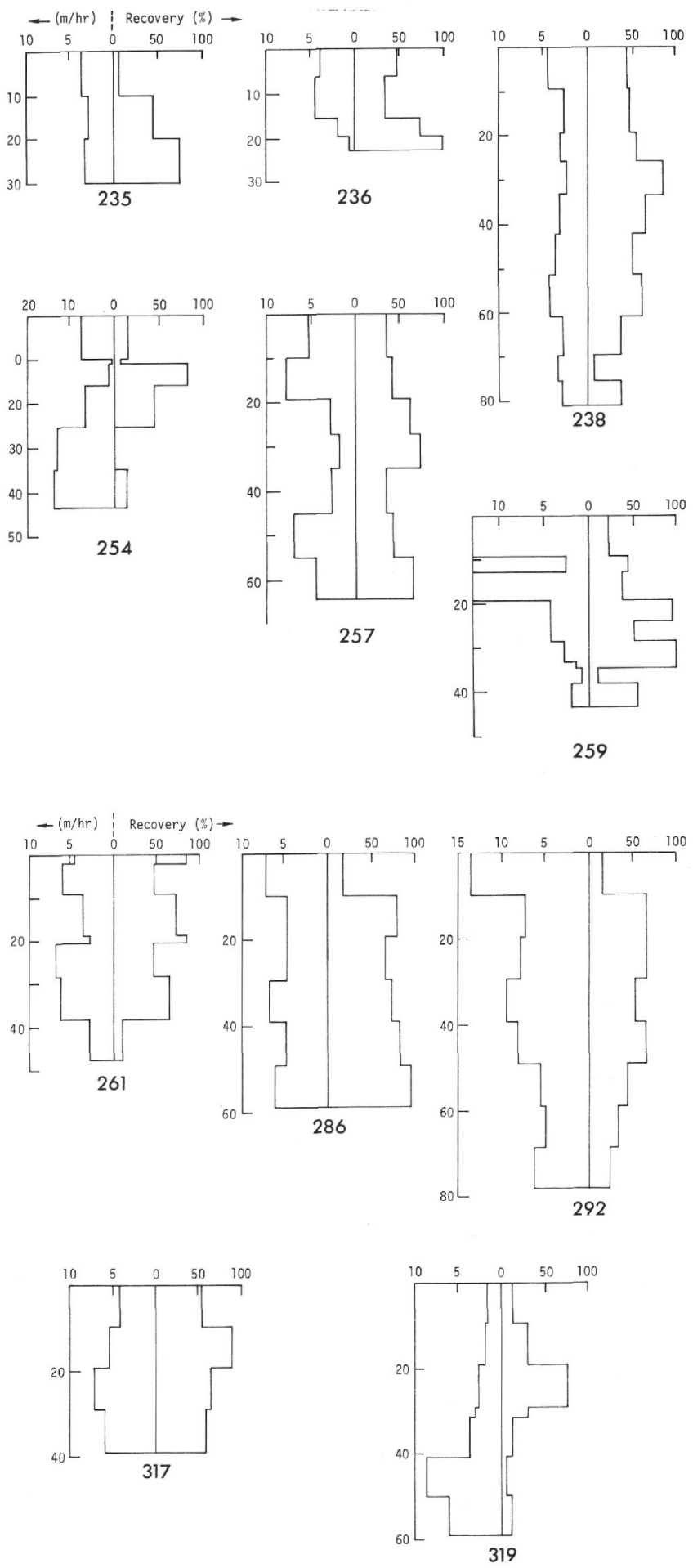

Figure 1. (A, B) Drilling rate $(\mathrm{m} / \mathrm{h})$ and core recovery $(\%)$ as a function of penetration depth for 11 sites which cored more than 20 meters of basement. 

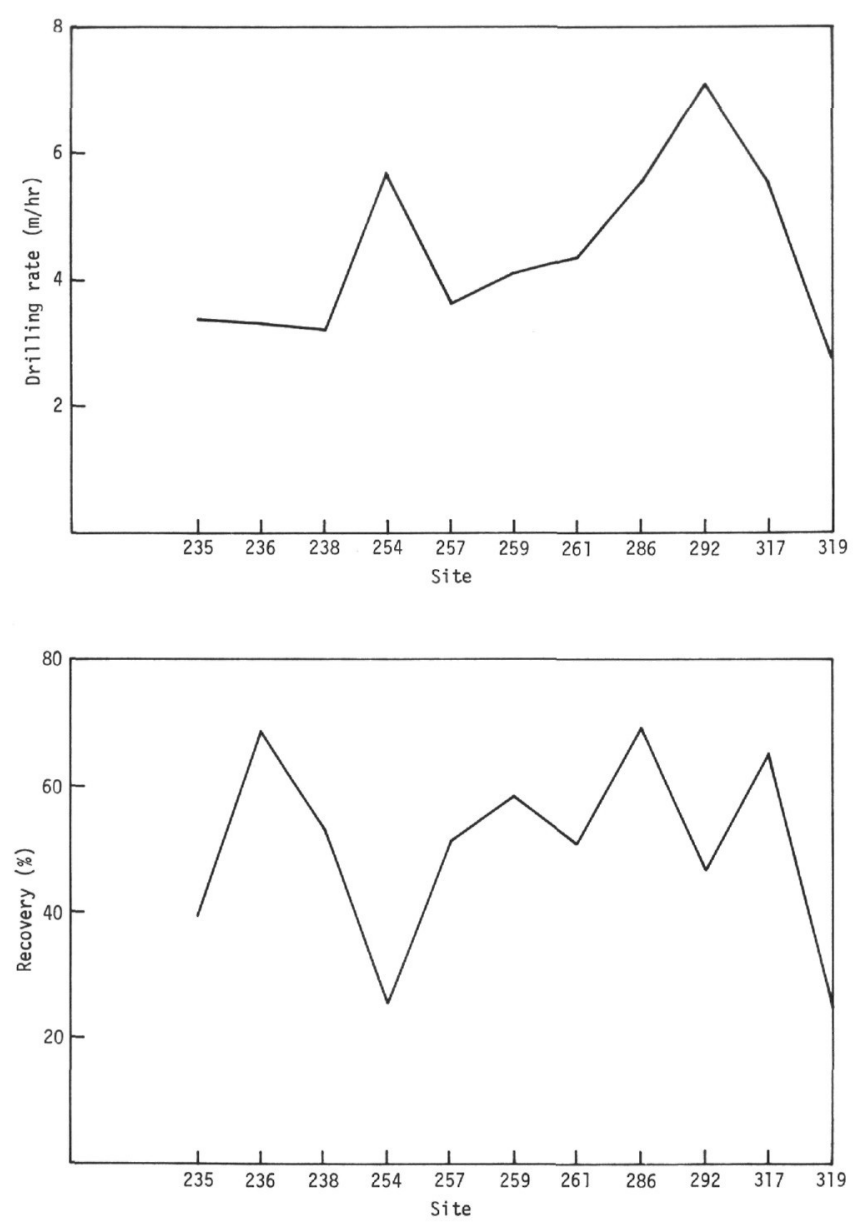

Figure 2. Drilling rate and core recovery for 11 sites plotted in chronological order.

starting a rat-hole, grinding up the basalt rather than coring it, a suggestion made in the Leg 16 Initial Report (Yeats et al., 1973, p. 617-618). Except for the topmost core, percent core recovery does not seem to vary systematically with depth.

4) There is no systematic change in coring rate with depth of basalt penetration.

5) There is no overall correlation between rate of recovery with either sediment overburden thickness or basement age (Figures 3 and 4). However, the lower bounds of the data for coring rate and recovery do seem to increase both with age and sediment thickness. This suggests that the probability of high coring rates and good recovery will be increased for older sites with relatively thick sediment overburden. The three sites with the highest coring rates on Figures 3 and 4 were reported to consist either of highly vesicular basalt or of basalt which was judged to have been extruded at relatively shallow depths. These sites may thus prove anomalous in terms of typical basement drilling experience, and may disguise possible trends in these figures.

6) There is a marked relationship (Figure 5) between coring rate and the compressional wave velocity (as measured on board at $1 \mathrm{~atm}$ pressure with the Hamilton frame). As several investigators have noted a decrease in velocity of layer 2 materials with increasing degree of
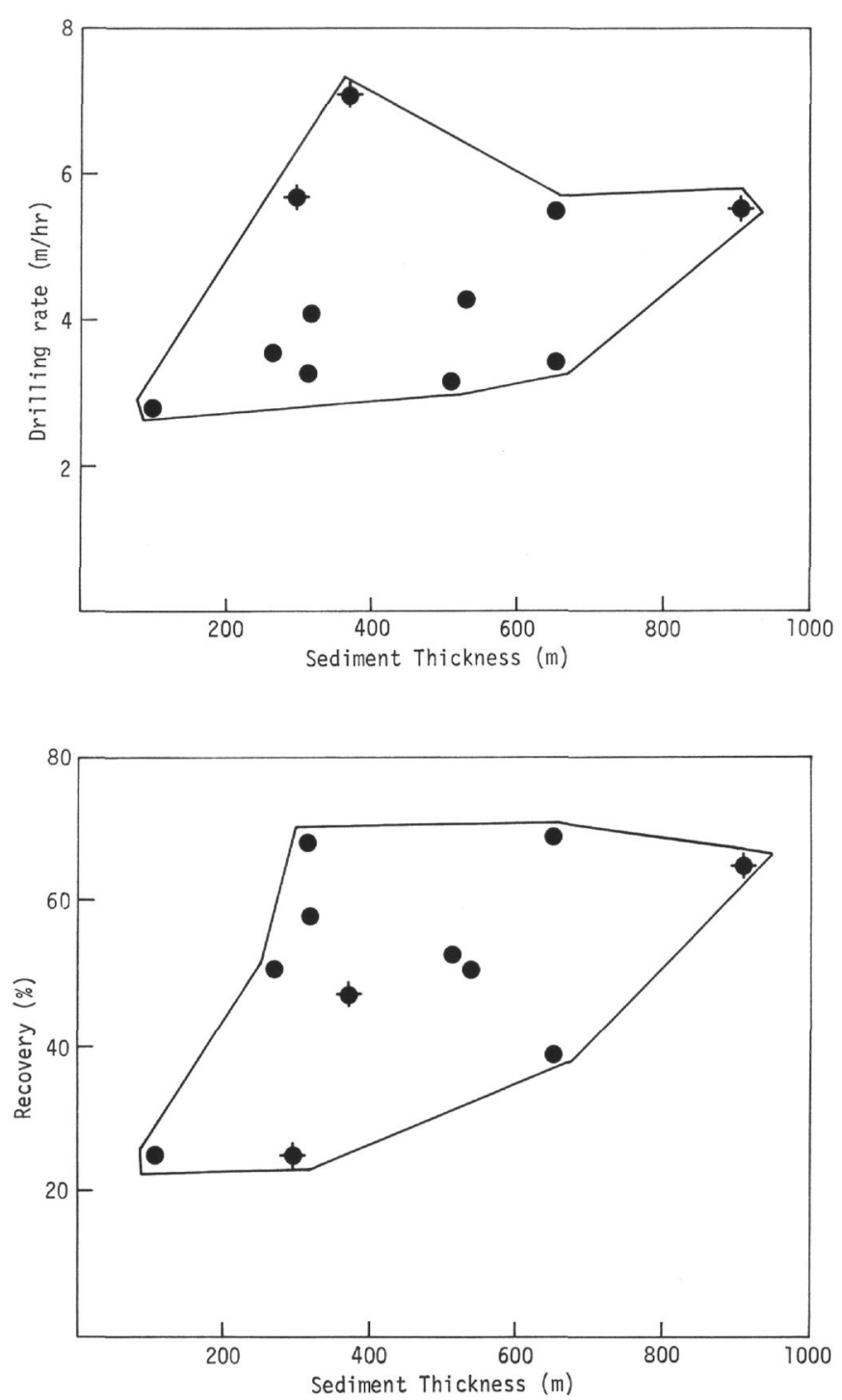

Figure 3. Drilling rate and core recovery as a function of overlying sediment thickness. The three points marked by a solid circle with cross are those which were reported either to be highly vesicular basalt or basalt believed to be extruded at relatively shallow depth.

alteration (Christensen and Salisbury, 1972; Hart, 1973), we feel the trend shown in Figure 5 simply reflects the greater ease with which altered materials may be drilled. This conclusion is born out also by the average water contents of rock recovered from these sites (Figure 6) and the general description of the rocks (degree of alteration), given in the site reports. However, R.E. Boyce (personal communication, 1974), taking into account a larger number of sites (including those with less than $20 \mathrm{~m}$ penetration), suggests that the more altered rocks have a slower drilling rate.

7) The only basement hole with greater than 20 meters penetration which encountered serious tight-hole conditions was Site 319 , which was abandoned at 59 meters due to almost continuous bit-sticking problems. This site had the least sediment overburden $(100 \mathrm{~m})$ and recovered the freshest and densest basalt of any of the 11 sites studied in this evaluation. We have not yet made a 

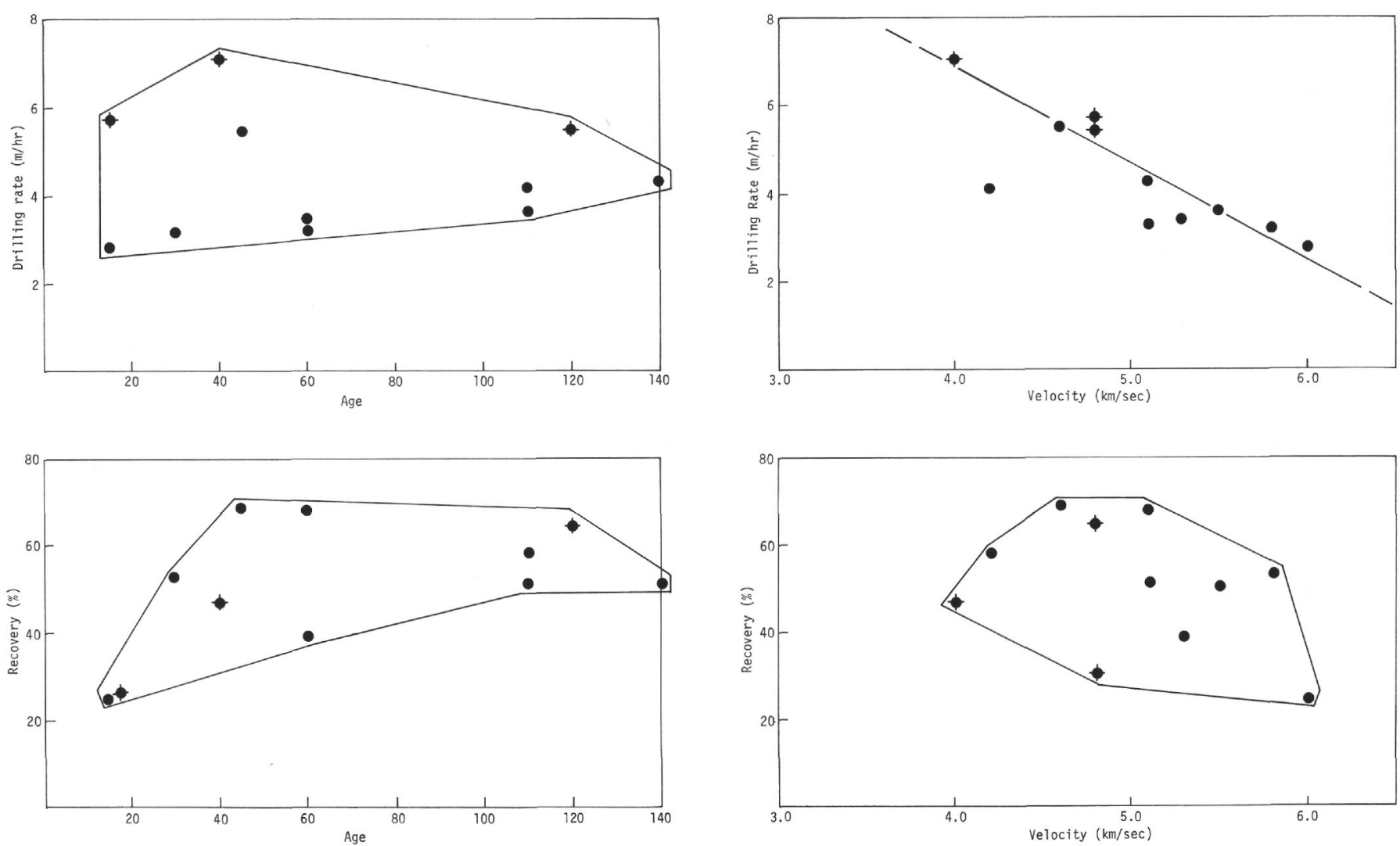

Figure 4. Drilling rate and core recovery as a function of age of oldest overlying sediment. Points marked with a solid circle with cross are explained in Figure 3 legend.

Figure 5. Drilling rate and core recovery compared with compressional wave velocity (as measured at 1 atm on shipboard with Hamilton frame).

TABLE 1

Coring Data for Basement Drilling

\begin{tabular}{cccccccc}
\hline Site & $\begin{array}{c}\text { Coring Rate } \\
(\mathrm{m} / \mathrm{hr})\end{array}$ & $\begin{array}{c}\text { Recovery } \\
(\%)\end{array}$ & $\begin{array}{c}\text { Penetration } \\
(\mathrm{m})\end{array}$ & $\begin{array}{c}\text { Age } \\
(\mathrm{m} . \mathrm{y} .)\end{array}$ & $\begin{array}{c}\text { Sediment } \\
\text { Cover }(\mathrm{m})\end{array}$ & $\begin{array}{c}\text { Velocity } \\
(1 \mathrm{~atm})\end{array}$ & $\begin{array}{c}\mathrm{H}_{2} \mathrm{O}^{\mathrm{a}} \\
(\text { total \%) }\end{array}$ \\
\hline 235 & 3.4 & 39 & 29 & 60 & 652 & 5.3 & 5.1 \\
236 & 3.3 & 68 & 22 & 60 & 306 & 5.1 & 3.2 \\
238 & 3.2 & 53 & 80 & 30 & 506 & 5.8 & 2.2 \\
254 & 5.7 & 25 & 25 & 15 & 297 & 4.8 & 6.1 \\
257 & 3.6 & 51 & 64 & 110 & 262 & 5.5 & 1.8 \\
259 & 4.1 & 58 & 38 & 110 & 308 & 4.2 & 2.5 \\
261 & 4.3 & 51 & 48 & 140 & 532 & 5.1 & 2.0 \\
286 & 5.5 & 69 & 57 & 45 & 650 & 4.6 & - \\
292 & 7.1 & 47 & 76 & 40 & 368 & 4.0 & - \\
317 & 5.5 & 65 & 34 & 120 & 910 & 4.8 & - \\
319 & 2.8 & 25 & 59 & 15 & 100 & 6.0 & 0.7 \\
\hline
\end{tabular}

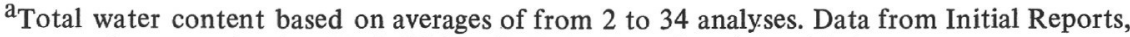
personal communication (R. L. Fisher, P. T. Robinson) and Leg 34 site report.

study of shallower penetration sites, but it is noteworthy that Site 219 drilled in 110 meters of sediment, was abandoned after 5 meters of basalt penetration due to high bit torques and bit sticking. Our feeling at this point is that unaltered basalt sites under minimal lithostatic load may consist of zones of loose fragmental blocks, uncemented hyaloclastites, etc, which will generate serious hole-caving problems. Alteration may tend to cement such loose blocks, with further consolidation (and perhaps cementation) enhanced by lithostatic load provided by sediment overburden. Bit sticking at Site 319 was confined to certain zones of poor recovery, thus we do not feel that the buildup of cuttings in the re-entry cone can be blamed for the hole conditions. Tight holes will remain a serious problem until it becomes technologically feasible to run casing through such zones.

\section{RECOMMENDATION}

It appears from these data that future deep basement drilling sites should be carefully evaluated in advance to 

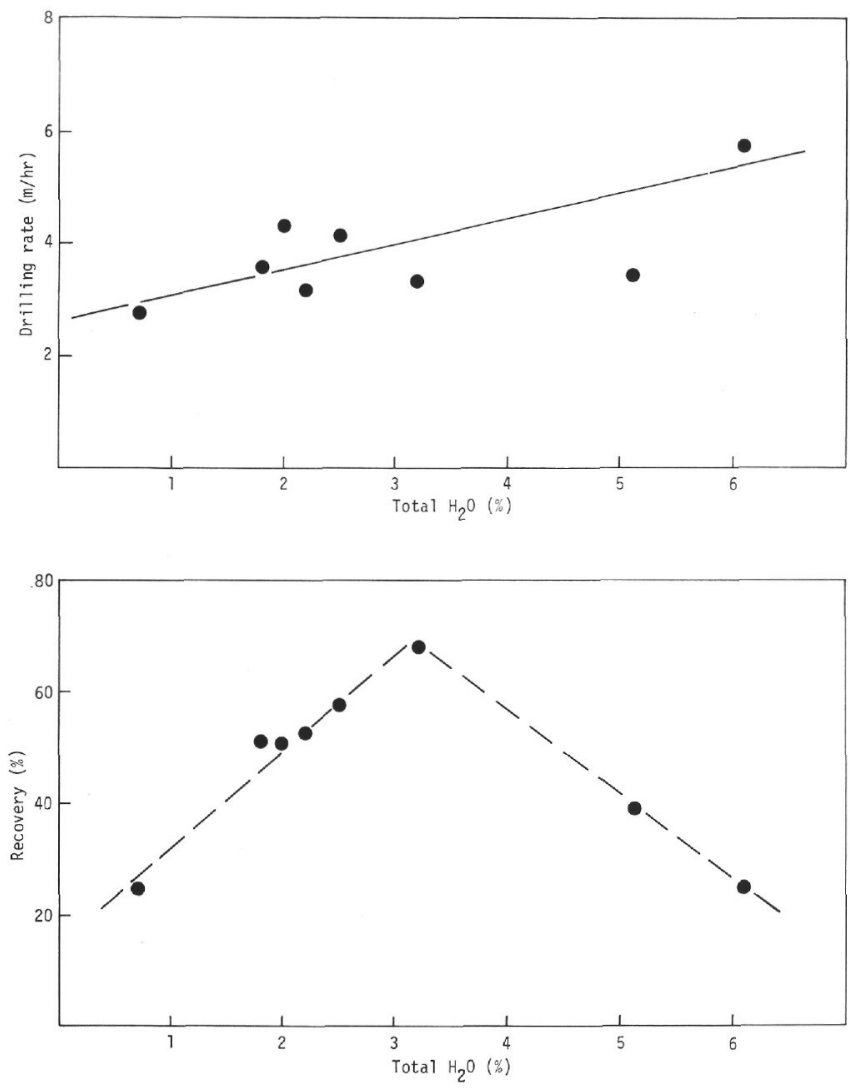

Figure 6. Drilling rate and core recovery compared with average total water contents of recovered basement samples. See Table 1 for source of these data. optimize chances for deep penetration. Sites should be chosen in an area of maximum sediment overburden (300-500 m or more), where velocity, petrographic, or chemical data from shallower penetrations in the surrounding areas show the rock to be suitably altered. We realize that from the scientific point of view, altered rock is not optimal for many studies; however, at present, the on-shore techniques for "seeing through" rock alteration seem to be more successful than the drilling techniques for penetrating fresh, unconsolidated pillow. basalt zones, etc. The basic structure of layer 2 can be deduced even from highly altered materials, and many chemical and paleomagnetic aspects can be determined despite considerable alteration.

Results from deep penetrations by DSDP Leg 37 indicate that these conclusions may not be valid for drilling in the Atlantic. However, the conclusions do seem valid for the sites in the Pacific and Indian oceans we considered.

\section{REFERENCES}

Hart, R., 1973. A model for chemical exchange in the basaltseawater systems of oceanic layer II: Can. J. Earth Sci., v. 10, p. 799.

Christensen, N.I. and Salisbury, M.H., 1972. Sea-floor spreading, progressive alteration of layer 2 basalts, and associated changes is seismic velocities: Earth Planet. Sci. Lett., v. 15, p. 307.

Yeats, R.S., Forbes, W.C., Heath, G..R., and Scheidegger, K.F., 1973. Petrology and geochemistry of DSDP Leg 16 basalts, eastern equatorial Pacific: In Van Andel, T.H., Heath, G.R., et al., Initial Reports of the Deep Sea Drilling Project, Volume 16: Washington (U.S. Government Printing Office), p. 617-640. 